Rudin, D. and I. EKBERG (1978): Linkage studies in Pinus sylvestris L.-using macro gametophyte allozymes. Silvae Genetica 27: 1-12.

SHAW, D. V. and R. W. Allard (1981): Analysis of mating system parameters and population structure in Douglas-fir using single-locus and multi-locus methods, pp. 18-22. In: Proc. Symp. Isozymes North Am. Forest Trees and Forest Insects edited by ConkLE, M. T.,
Berkeley, C. A. USDA Forest Serv. Gen. Techn. Rep. PSW-48.

Strauss, S. H. and M. T. ConkLE (1986): Segregation, linkage and diversity of allozymes in knobcone pine. Theor. Appl. Genet. 72: 483-493.

SzmidT, A. E. and O. MuONA (1989): Linkage relationships of allozyme loci in Pinus sylvestris. Hereditas 111: 91-97.

\title{
Genetic Diversity and Gene Flow of Quercus crispula in a Semi-Fragmented Forest Together With Neighboring Forests
}

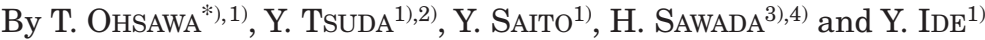

(Received $26^{\text {th }}$ October 2005)

\begin{abstract}
The genetic diversity and differentiation in Quercus crispula populations in the Chichibu Mountains, central Japan, were evaluated using six microsatellite markers. Gene flow into a $2500-\mathrm{m}^{2}$ semi-fragment of a natural forest from the neighboring natural forest at a distance of more than $50 \mathrm{~m}$ was also evaluated using parentage analysis. All five populations in the mountains had similar levels of genetic diversity $\left(H_{\mathrm{e}}=0.752-0.792\right)$, and the level of population differentiation was low $\left(F_{\mathrm{ST}}=0.016\right)$. The semi-fragmented stand showed similar genetic diversity with the neighboring unfragmented forests, and Hardy-Weinberg disequilibrium was not found $\left(F_{\text {IS }}=0.083\right.$ in adults, 0.025 in seedlings $)$. In the semifragment, 70 seedlings were examined; according to the parentage analysis, eight of the 70 seedlings (ca. 11\%) had neither of the parent trees in this fragment. These seeds must have been transported from a distance of more than $50 \mathrm{~m}$; therefore, there could be a possibility that the seeds were dispersed by birds. A similar trend of seed flow into the fragment was also confirmed by genotyping endocarps of hypogeal cotyledons, while more frequent seed flow was found in the neighboring unfragmented forest. Of the remaining 62 seedlings, the maternal trees (but not the paternal trees) of 29
\end{abstract}

1) Department of Ecosystem Studies, Graduate School of Agricultural and Life Sciences, the University of Tokyo, Yayoi 1-1-1, Bunkyo-ku, Tokyo 113-8657, Japan.

2) Forest and Forest Production Research Insitute, Matsunosato 1, Tsukuba-shi, Ibaraki 305-8687, Japan.

3) University Forest in Chichibu, Graduate School of Agricultural and Life Sciences, the University of Tokyo, Hinoda 1-1-49, Chichibu-shi, Saitama 368-0034, Japan.

4) University Forest in Aichi, Graduate School of Agricultural and Life Sciences, the University of Tokyo, Goizuka 11-44, Seto-shi, Aichi 489-0031, Japan.

*) Communicating author: TAKAFUmi OHSAWA, Department of Ecosystem Studies, Graduate School of Agricultural and Life Sciences, the University of Tokyo, Yayoi 1-1-1, Bunkyo-ku, Tokyo, Japan. Phone: +81-03-5841-8208. Email: aa56258@mail. ecc.u-tokyo.ac.jp seedlings and both parent trees of 33 seedlings were detected in the semi-fragment. These results indicate that the gene flow among the populations occurs frequently via pollen dispersal and occasionally via seed dispersal and that, at least the current levels of genetic diversity have been maintained in such fragmented forests.

Key words: forest fragmentation, microsatellites, parentage analysis, Quercus crispula.

\section{Introduction}

Since many years, forest fragmentation has resulted from human activities and has been affecting many ecosystems worldwide, including Japan. A geographic information system (GIS) analysis revealed that $53 \%$ of forest patches were smaller than 1ha even in rural area (MiYAmoto and SHIMAdA, 2001). In this country, semifragmented natural stands located close to neighboring natural stands are found more frequently rather than those far away from other natural stands. This is partly due to the construction of roads and buildings in the natural forests as seen in other countries. Many trunk roads with a width of several ten meters run through the natural forests. In addition, many mountains are occupied by various small stands due to cutting or planting activities of private small-scale forest owners (KONOHIRA, 1996). Approximately $41 \%$ of all forests in Japan are man-made (ANON, 1994), and this percentage is much higher than that in other countries. The unique geographical feature of Japan is one of the reasons for the large number of semi-fragmented natural stands. Of the total Japanese land area, 75\% is classified as mountainous or hilly, and $60 \%$ of the forest area is characterized as having a slope of $20^{\circ}$ or more (HANDA, 1988). Many areas consist of very steep rocky slopes. Consequently, natural stands are often found on partially steep slopes; these are inappropriate for afforestation. Therefore, these semi-fragments are at short distances 
of several ten to hundred meters form the neighboring natural stands. Completely isolated populations of endangered species or alpine plants are found worldwide, and studies on these fragmented populations have been widely published. However, whether the semi-fragments of common species found in Japan will be maintained in the future and the method by which they will be maintained remain unknown.

In terms of ecology, the forest fragmentation has been actively investigated with edge effects, though there is substantial discrepancy among recent studies about the existence and intensity of edge effects (MURCIA, 1995). For example, a tree census in two isolated stands in 1989 and 2000 was carried out to determine the structural changes in a small lucidophyllous tree population in Japan following fragmentation (KominAMI et al., 2003). Although it was found that five tree species were lost over an 11-year period, no changes in structural or population characteristics were regarded as being due to forest fragmentation. However, such studies would not clearly detect the influence of forest fragmentation (if any) because they do not consider seed dispersal or genetic erosion, which can cause long-term changes.

On the other hand, rapid developments in molecular biological techniques such as allozyme and microsatellite analyses have greatly increased the power and scope of genetic research on habitat fragmentation. Theoretically, the fragmentation of populations should lead to an erosion of genetic variation and increased inter-population genetic divergence through: (1) increased random genetic drift, (2) increased inbreeding, (3) reduced interpopulation gene flow, and (4) increased probability of local extinction of demes within meta-populations (Young et al., 1996). Forest fragmentation may have three main effects (IsAGI, 2004): (1) no detectable genetic changes may occur in the tree population because the trees have a long life span, and they retain the genetic diversity possessed prior to fragmentation; (2) it may have detectable adverse effects on pollination, seed dispersal, and the genetic traits of reproductive plants; or (3) it may change the foraging patterns of insects or animals so as to promote pollen and seed dispersal. In particular, the second effect, which is consistent with the mentioned theory of Young et al. (1996), has been reported in many studies. For example, a microsatellite analysis by DAYANANDAN et al. (1999) revealed that the allelic richness was low in the sapling cohort of the isolated populations of Carapa guianensis. On the other hand, BACLES et al. (2004) found that remnants of Sorbus aucuparia maintained high levels of genetic diversity in isozyme and cpDNA markers such as the non-fragmented populations. However, the pollen-mediated gene flow has decreased due to forest fragmentation, and the high levels of genetic diversity within the remnants are maintained probably due to the help of effective seed dispersal by birds. The third effect has also been reported in some recent studies. For example, Dick (2001) reported that Dinizia excelsa inhabiting fragmented forests produced, on an average, over three times as many seeds as those produced by the trees in continuous forests. Furthermore, the microsatellite assays of seed arrays performed by DICK (2001) showed that genetic diversity was maintained across habitats. A fragmented population of Fraxinus excelsior has also maintained genetic diversity at high levels than those reported for continuous populations (BACLES et al., 2005). BACLES et al. (2005) suggested that the opening of the landscape facilitated airborne pollen movement, thereby alleviating the expected detrimental genetic effects of fragmentation. As described above, the potential effects of forest fragmentation are highly varied. A recent study suggested that approaches based on life-history traits potentially permit the prediction of the species' response to forest fragmentation (KolB and DiEKMANN, 2004). However, further studies will be required in order to verify these approaches.

Quercus crispula Blume (Fagaceae) is a common tree species widespread in the cool-temperate deciduous forests of southern Sakhalin, the Kuril Islands, Japan, and Korea. It is an intermediately shade-tolerant species that is capable of sustained regeneration and has a life span of several hundred years; it attains a maximum height and diameter of $30 \mathrm{~m}$ and $1.5 \mathrm{~m}$, respectively (WATANABE, 1994). Q. crispula is monoecious and a highly outcrossed, wind-pollinated species (WATANABE, 1994). Its seeds are dispersed by gravity or rodents (Apodemus spp. and Sciurus spp.) and birds (Garrulus spp. and Nucifraga spp.); it thus provides important food for animals. Almost all of these life-history traits appear advantageous in alleviating the genetic effects of forest fragmentation. Nevertheless, Q. crispula exhibits a relatively high level of inbreeding depression, and it was suggested that inbreeding individuals would have a high mortality rate within each patchy structure (UBUKATA et al., 1999). Hence, despite its several advantageous life-history traits, even small isolations can seriously affect $Q$. crispula population through inbreeding within fragments. Moreover, very steep rocky slopes with poor soil are not suitable for artificial forests and $Q$. crispula populations. On such slopes, populations of this species will probably need to propagate the next generation under severe conditions, and effects of even slight fragmentation can have a serious impact on them.

The objective of this study was to evaluate the effects of forest semi-fragmentation on $Q$. crispula. We examined the genetic diversity and differentiation of populations in this species in the Chichibu Mountains, central Japan. The genetic diversity in a semi-fragmented stand and the gene flow into the fragment from other sources were also studied. Here, we describe the results of these analyses and discuss their implications regarding the characteristics and management of the fragmented natural forests, particularly in Japan.

\section{Materials and Methods}

\section{Study site and sampling}

This study was performed in the University Forest in Chichibu, The University of Tokyo, (138 $\left.48^{\prime} \mathrm{E}, 35^{\circ} 56^{\prime} \mathrm{N}\right)$ located in the central area of Japan (Fig. 1). The mean annual temperature in the area is $10.9^{\circ} \mathrm{C}$, the annual precipitation amounts to $1400-1500 \mathrm{~mm}$ and the maximum snow depth from winter to early spring is usually less than half a meter (UNIVERSITY FoREST IN CHICHIBU, 


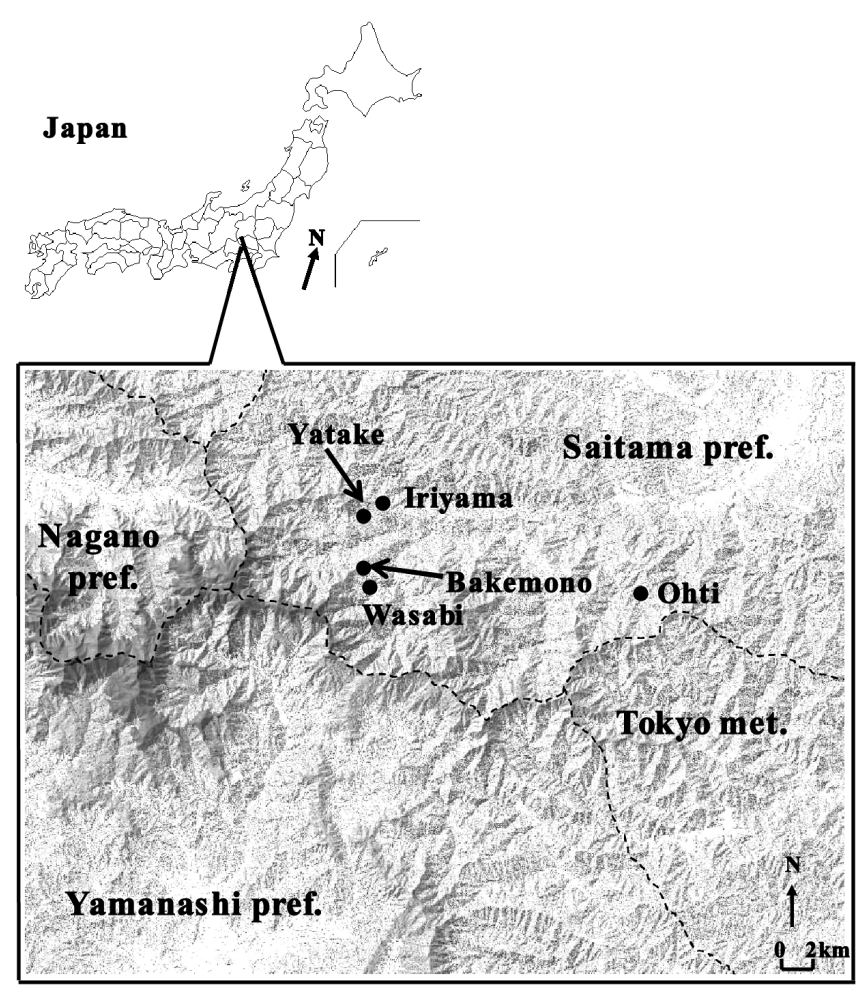

Figure 1. - Location of the sampled five populations of Quercus crispula in the Chichibu Mountains.

2002). The mountains are mostly covered with cool temperate second-growth forests dominated by species such as oak or beech, while man-made forests of species like Cryptomeria japonica or Chamaecyparis obtusa, occupy some areas (UNIVERSITY FOREST IN CHICHIBU, 2002). The major oak species in this region are $Q$. crispula and $Q$. serrata, the latter predominantly in warmer areas than $Q$. crispula. In some area, both species coexist and hybridize with each other. The slopes are typically very steep, especially in the lower portions of the valleys, due to severe erosion and the formation of a V-shaped valley by the Arakawa River. To elucidate the genetic diversity and differentiation in this region, leaf samples for genetic analysis were randomly collected in the summer of 2004 from five populations (Iriyama, Yatake, Ohchi, Bakemono, and Wasabi; Table 1). The number of individuals sampled per population ranged from 23 to 49 . The collected samples were stored at $-80^{\circ} \mathrm{C}$ until DNA extraction.

Table 1. - Topographic conditions for each of the five populations of Quercus crispula in the Chichibu Mountains.

\begin{tabular}{cccc}
\hline population & altitude $(\mathrm{m})$ & direction & slope $\left(^{\circ}\right)$ \\
\hline Iriyama & $1200-1400$ & $\mathrm{SW}$ & 34 \\
Yatake & $1100-1300$ & $\mathrm{E}$ & 27 \\
Ohchi & $700-1000$ & $\mathrm{NW}$ & 21 \\
Bakemono & $1100-1400$ & $\mathrm{SW}$ & 31 \\
Wasabi & $1100-1300$ & $\mathrm{NE}$ & 39 \\
\hline
\end{tabular}

To describe the gene flow into a fragmented stand from outside, we investigated a semi-fragmented stand and one plot in unfragmented stand located on the same, southwest-facing hillside named "Iriyama" (Fig. $2)$. The semi-fragmented stand had been connected with the neighboring natural forest until about 30 years ago. The semi-fragmented stand is composed of 35 mature oak trees (33 Q. crispula and 2 Q. serrata), in a triangular area of $2500 \mathrm{~m}^{2}$, situated on a steep slope (mean gradient $31^{\circ}$ ). Such steep areas with poor soil escaped afforestation, although the surrounding forest has been changed into artificial conifer forests. The nearest natural forest to this stand is $50 \mathrm{~m}$ away, and it is one of the typical examples of semi-fragmented forest in Japan. The species composition of the stand was very similar to that of the neighboring natural forest because of the past connection. These forests were secondary deciduous forests dominated by oak ( $Q$. crispula), beech (Fagus crenata), and maple (Acer spp.). The mean age of the oak trees is around 70 years, and therefore these trees had germinated before the fragmentation. No dwarf bamboo was present in the fragmented stand, although there were some colonies in the neighboring forest. We had already collected leaves of adults randomly in "Iriyama" including the semi-fragment and the neighboring natural forest to elucidate the genetic diversity and differentiation, but another time we collected leaves of all 35 adults in the fragmented plot. Moreover, leaves of nearly all seedlings germinated from May to July in this year were collected. The endocarps of hypogeal cotyledons were also sampled in the fragmented plot, where possible, since they are of maternal origin, allowing the seeds' mother trees to be identified (GODOY and JoRDANO, 2001; SUYAMA, 2004; GrIVET et al., 2005). Till quite recently, many researchers had used seedlings to detect the parents with some assumptions or maximum-likelihood approach. But the new method with genetic analysis of endocarps was developed lately, and it is now the most effective approach to identify mother trees with high accuracy. As a result, we obtained leaves of 70 seedlings and endocarps of 52 seedlings. To compare the local genetic diversity in and gene flow into the fragmented plot with those in the unfragmented forest, we then collected leaves of all 72 adults in a unfragmented plot covering an area of $2500 \mathrm{~m}^{2}$ on a relatively gentle slope (mean gradient $\left.19^{\circ}\right)$. Leaves of 238 seedlings were also collected for evaluating genetic diversity and 216 endocarps of them were collected for parentage analysis. The position of each individual was also recorded in the both plots. In addition, in the autumn of 2004 we collected 50 seeds randomly on the ground within $5 \mathrm{~m}$ in radius from two adults, designated Y126 and Y132, in the fragmented plot for supplementary assessment of pollen flow into the fragment from outside.

\section{Genetic analysis}

DNA was extracted by a modified CTAB procedure (LIAN et al., 2003). But the sampled endocarps had been buried under ground for more than half a year, and they included impurities. Therefore, the endocarp DNA often showed imperfect amplification in polymerase chain 


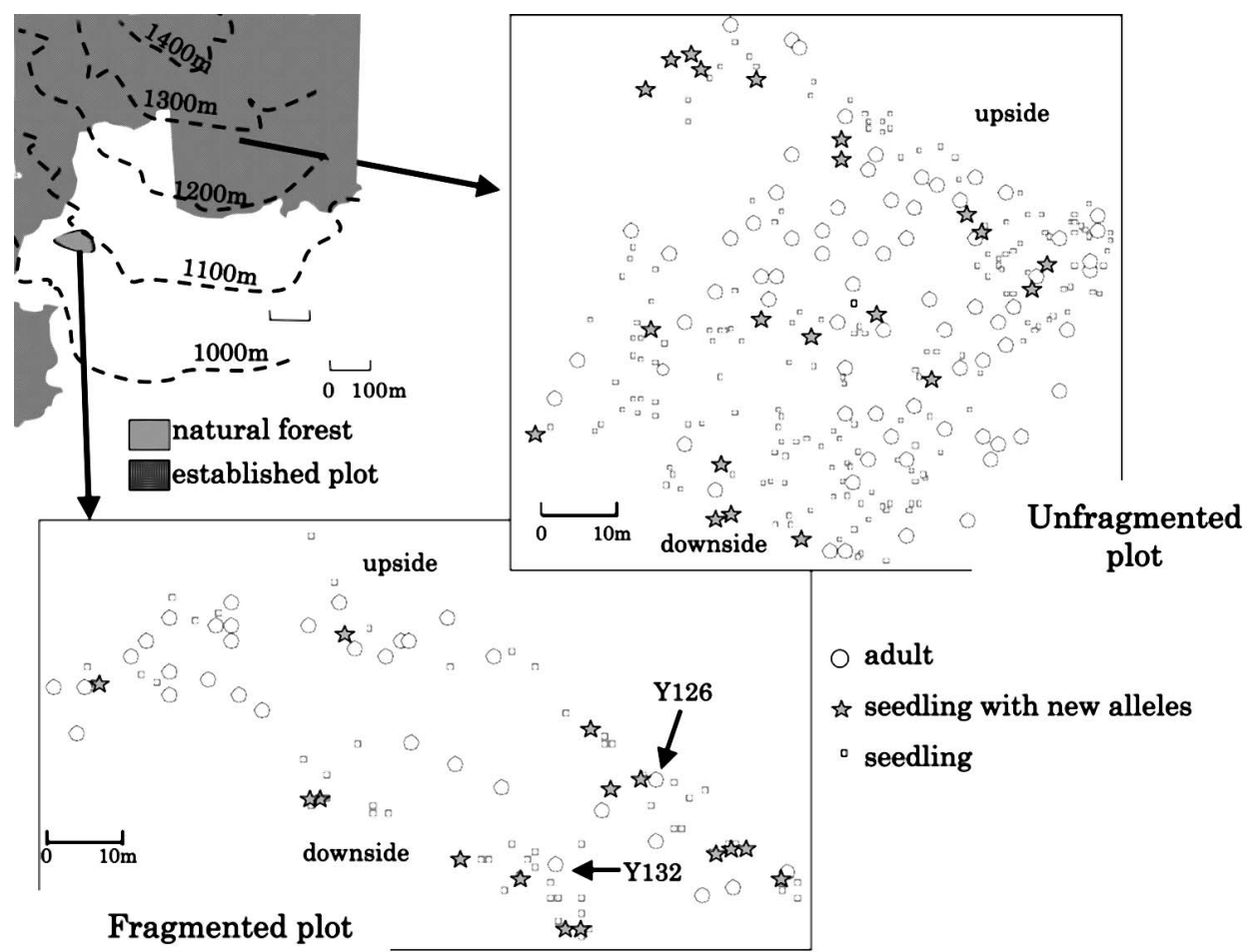

Figure 2. - Location of the two plots of Quercus crispula in Iriyama with contour lines and the individual maps within each plot. The fragmented plot is a semi-fragment of natural forest from the neighbor natural forest more than $50 \mathrm{~m}$ away, while the unfragmented plot is located in the middle of an unfragmented natural forest. On the individual maps, large stars indicate the seedlings with the new alleles which were not found in any adults within each plot. Large circles and small squares indicate then adults and other seedlings, respectively.

reaction (PCR) or amplified multi-band which could be difficult to be genotyped. To cope with these problems, the resulting extract of endocarps was purified using a Wizard SV Gel and PCR Clean-Up System (Promega). Extract was amplified by PCR, using a multiplex PCR Kit (QIAGEN), with six nuclear microsatellite (SSR) primer pairs in one tube: QpZAG1/5, QpZAG9, QpZAG15, QpZAG16, and QpZAG110 (STEINKELLNER et al., 1997) and MSQ13 (Dow et al., 1995). The $5.0 \mu \mathrm{l}$ amplification reaction mixtures included 2.5 $\mu$ l of MasterMix solution (QIAGEN), $1.3 \mu$ l of RNase-free water, $0.5 \mu$ l of primer mix solution, and $0.7 \mu l$ of the extracted DNA. The used primer mix solution included six primer pairs of $0.5 \mathrm{pmol} / \mu \mathrm{l}$. The reactions were performed with the following temperature program: 15 min denaturing at $95^{\circ} \mathrm{C}$ followed by 30 cycles of $30 \mathrm{~s}$ denaturing at $94^{\circ} \mathrm{C}$, $90 \mathrm{~s}$ annealing at $57^{\circ} \mathrm{C}$ and $60 \mathrm{~s}$ extension at $72^{\circ} \mathrm{C}$, with a final extension step of $60{ }^{\circ} \mathrm{C}$ for $30 \mathrm{~min}$. For the endocarp DNA, the PCR cycles were rearranged from 30 to 40 , to obtain sufficient amplification (to genotype). Finally, the PCR product was loaded into an ABI3100 Genetic Analyzer (Applied Biosystems) and amplified allele sizes were estimated using GeneMapper software (Applied Biosystems).

\section{Statistical Analysis}

Based on the derived genotypes, genetic diversity was estimated within each population by calculating the expected heterozygosity $\left(H_{\mathrm{e}}\right)$. Using rarefaction procedures to account for uneven sample sizes, allelic richness $\left(A_{[46]}\right)$ (Mousadik and PeTIT, 1996) was also calcu- lated based on the smallest number of genes sampled in one population. The inbreeding index $\left(F_{\text {IS }}\right)$ and their significance were also assessed with 1000 randomizations using the program FSTAT version 2.9.3.2. (GOUDET, 2001). The number of locus pairs showing significant genotypic disequilibrium $(G D)$ was estimated with the same program. The genetic differentiation between populations was evaluated by calculating overall fixation index $\left(F_{\mathrm{ST}}\right)$ (WEIR and CoCKERHAM, 1984). $95 \%$ and $99 \%$ confidence intervals were evaluated by 1000 bootstrap permutations, and the significance of genotypic population differentiation at each locus and over loci was tested by the log-likelihood $(G)$-based exact test (GoUDET et al., 1996) using FSTAT. The pairwise fixation index $\left(F_{\mathrm{ST}}\right)$ was also calculated, and its significance was assessed with 1000 randomizations using the same program.

In addition, for both adult and seedling groups in the two plots, expected heterozygosity $\left(H_{\mathrm{e}}\right)$, allelic richness $\left(A_{[70]}\right)$, inbreeding indices $\left(F_{\text {IS }}\right)$, and the number of locus pairs showing significant genotypic disequilibrium $(G D)$ were calculated using FSTAT. To detect gene flow from outside into the plots, we identified and counted new alleles that were present in the seedling group but not in the adult group. Additionally, the number of seedlings with these new alleles was counted.

\section{Parentage analysis}

We entered all possible genotypes for each seedling and adult into a database for all six of the markers. Before identifying the parent trees of seedlings in the 
fragmented plot, we calculated total exclusion probability (CHAKRAVARTI and LI, 1983) using the CERVUS program (MARSHALL et al., 1998) in order to estimate the resolution power of these six markers. We had the genotype information of endocarp which is useful to identify the parent trees of seedlings, but the number of successfully genotyped endocarps was limited (see the results). So we conducted simple parentage exclusion following the classic procedure of Dow and ASHLEY (1996) before using the genotype information of endocarp. First, if a seedling matched no adult in the forest fragment, its parent trees were assumed to be located outside of the fragment. Second, if a seedling matched only one adult in the fragment, the matching adult was assumed to be its maternal tree. This is because a seed developed from a female flower located outside the fragment with pollen from inside is considered to have been transported into the fragment with little probability. Third, if a seedling matched multiple adults in the forest, both of its parent trees were assumed to be present in it. We then detected adult trees that genotypically matched the 36 endocarps in order to confirm that seeds were dispersed into this stand. Because of the low quality of endocarp DNA (mentioned above), amplified multibands can be found with three markers (QpZAG9, QpZAG15, and QpZAG110). So the other three markers (QpZAG1/5, QpZAG16, and MSQ13) were used for this part of the investigation. For reference, the dispersal distances of pollen and seed were then calculated based on the positions of seedlings together with their putative parents within the plot. On the other hand, the mother trees of seedlings in the unfragmented plot were also identified with 172 genotyped endocarps at the three markers. If more than one trees genotypically matched endocarps, other three markers were also used exceptionally to identify the true mother tree. The seed dispersal distance was then calculated like the fragmented plot.

Based on the results of our analysis of embryonic tissues and endocarps from the seeds collected in the autumn, we gathered data on seeds whose endocarps genotypically matched either of the two target adults at the three markers. Then, whether their father trees existed in the fragmented plot or not was checked by simple exclusion with all six markers in order to assess the extent (if any) of pollen flow into the forest fragment from the outside.

\section{Results \\ Genetic diversity and differentiation of Q. crispula populations in the Chichibu Mountains}

Genetic diversity result based on the six nuclear microsatellites is summarized in Table 2. Each population had similar, high levels of genetic variation $\left(H_{\mathrm{e}}=\right.$ $\left.0.752-0.792, A_{[46]}=8.050-9.124\right)$. The inbreeding coefficient was not deviated significantly from 0 in any populations, and no locus pairs showing significant genotypic disequilibrium were found. The $F_{\mathrm{ST}}$ value was 0.016 with confidence intervals of $0.011-0.021$ (95\%) and $0.010-0.023(99 \%)$, which showed that the level of population differentiation was very low. Genetic differentiation among populations measured by pairwise $F_{\mathrm{ST}}$ is shown in Table 3 which indicates that Wasabi and Bake-
Table 2. - Sample number, expected heterozygosity, allelic richness, inbreeding coefficient and number of locus pairs showing significant genotypic disequilibrium in five Quercus crispula populations based on six SSR loci.

\begin{tabular}{cccccc}
\hline & $N$ & $H \mathrm{e}$ & $A_{[46]}$ & $F_{\mathrm{IS}}$ & $G D$ \\
\hline Iriyama & 49 & 0.792 & 9.124 & 0.029 & 0 \\
Yatake & 43 & 0.787 & 8.855 & 0.069 & 0 \\
Ohchi & 37 & 0.756 & 8.613 & -0.023 & 0 \\
Bakemono & 23 & 0.753 & 8.508 & -0.006 & 0 \\
Wasabi & 26 & 0.752 & 8.261 & 0.139 & 0 \\
\hline
\end{tabular}

$N$ : number of individuals, $H_{\mathrm{e}}$ : expected heterozygosity, $\mathrm{A}_{[46]}$ : allelic richness, $F_{\text {IS }}$ : coefficient of inbreeding, $G D$ : number of locus pairs showing significant genoptypic disequilibrium.

Table 3. - Genetic differentiation measured by pairwise $F_{\mathrm{ST}}$ (WEIR and COCKerHAM, 1984) (above diagonal) and geographic distance (km: below diagonal) among five Quercus crispula populations.

\begin{tabular}{lccccc}
\hline & Iriyama & Yatake & Ohchi & Bakemono & Wasabi \\
\hline Iriyama & & $*^{*} 0.0059$ & ${ }^{*} 0.0190$ & ${ }^{\mathrm{NS}} 0.0122$ & $*_{0.0158}$ \\
Yatake & 1 & & $*^{*} 0.0206$ & ${ }^{\mathrm{NS}} 0.0120$ & ${ }^{*} 0.0185$ \\
Ohchi & 17 & 17 & & ${ }^{*} 0.0265$ & ${ }^{*} 0.0190$ \\
Bakemono & 5 & 4 & 16 & & ${ }^{\mathrm{NS}} 0.0192$ \\
Wasabi & 5 & 5 & 16 & 1 & \\
\hline
\end{tabular}

$P$-values determined using 1000 replicates.

$*: P<0.05$, NS: not significant.

mono are somewhat differentiated in spite of the short geographic distance between them.

\section{Genetic diversity within two plots, and gene flow into these plots from outside sources}

Individual maps of areas within the two plots are shown in Fig. 2, while the results of the genetic diversity analyses of the plots are shown in Table 4 . The expected heterozygosity and allelic richness ranged from 0.719 to 0.779 and from 8.670 to 10.333 , respectively. The inbreeding coefficients showed no significant deviation from zero.

In the fragmented plot, 14 alleles were found in 15 seedlings, but not in adults. The total exclusion probability with six markers was 0.9967 and 0.9998 for the first and second parents, respectively. Hybrid seedlings of $Q$. crispula and $Q$. serrata were not found in the samples. No putative parent trees were identified for eight of the 70 seedlings genotyped in the plot. Of the remaining 62 seedlings in the plot, maternal trees, but not paternal trees, were found for 29 seedlings; both parent trees were found for 33 seedlings. Extracting DNA from the endocarps was difficult due to its low quality for PCR; however, approximately $70 \%-80 \%$ of the endocarps were genotyped with respect to three markers 
Table 4. - Sample number, expected heterozygosity, allelic richness, inbreeding coefficient and number of locus pairs showing significant genotypic disequilibrium in two Quercus crispula plots. The fragmented plot is a semi-fragment of natural forest from the neighbor natural forest more than $50 \mathrm{~m}$ away, while the unfragmented plot is located in the middle of an unfragmented natural forest. Both plots cover an area of $2500 \mathrm{~m}^{2}$ respectively.

\begin{tabular}{lccccc}
\hline & $N$ & $H \mathrm{e}$ & $A_{[70]}$ & $F_{\text {IS }}$ & $G D$ \\
\hline Adults in the fragmented plot & 35 & 0.779 & 10.333 & 0.083 & 0 \\
Seedlings in the fragmented plot & 70 & 0.755 & 9.663 & 0.025 & 0 \\
Adults in the unfragmented plot & 72 & 0.719 & 8.738 & 0.012 & 0 \\
Seedlings in the unfragmented plot & 238 & 0.745 & 8.670 & 0.026 & 0 \\
\hline
\end{tabular}

$N$ : number of individuals, $H_{\mathrm{e}}$ : expected heterozygosity, $A_{[70]}$ : allelic richness, $F_{\mathrm{IS}}$ : coefficient of inbreeding, $G D$ : number of locus pairs showing significant genotypic disequilibrium.

(QpZAG1/5, QpZAG16, and MSQ13). Of the 36 successfully genotyped endocarps in the fragmented plot, 32 endocarps matched with one adult in the plot (Table 5). Thus, four of the 36 seedlings were from sources outside the plot. The mean distance of pollen and seed dispersal within the plot were $29.7 \mathrm{~m}(\mathrm{SD}: \pm 18.6)$ and $16.8 \mathrm{~m}$ (SD: \pm 11.1 ), respectively. In the unfragmented plot, 13 alleles were found in 21 seedlings, but not in adults. Of the 172 genotyped endocarps, 108 matched with only one adult, and 3 matched with two adults, respectively at the three markers in the plot. However, the true maternal trees of the three seedlings were also identified from multiple candidates with three other markers. Consequently, 61 of the 172 seedlings were from sources outside the plot (Table 5). The mean seed dispersal distance within the unfragmented plot was $10.38( \pm 8.0) \mathrm{m}$.

In the autumn, we collected and genotyped 50 samples near each target tree, but only 16 and 17 seeds were identified as seeds of the two target adults (Y126 and Y132, respectively). Other seeds were come from adjacent adults in the fragmented plot. In addition, no father trees in this plot could be identified for ten of the 16 seeds dispersed from Y126 and twelve of the 17 seeds from Y132. Thus, the tendencies detected by the dis- persed seeds analysis regarding pollen flow into the plot were similar to those found in the seedling analysis.

\section{Discussion}

Most previous studies of oak species have found high genetic diversity. Based on an analysis of six microsatellite markers, for example, in two forests in northern Britain, CotTrELl et al. (2003) found high expected heterozygosity values, ranging from 0.87 to 0.92 in $Q$. robur and $Q$. petraea. MARIETTE et al. (2002) assessed genetic diversity within populations of $Q$. robur and $Q$. petraea with six microsatellite marker, and the values of $H_{\mathrm{e}}$ ranged from 0.835 to 0.908 . Considering these results, the populations of $Q$. crispula in the Chichibu Mountains have similar diversity to other oak stands. Addition to this, genetic differentiation among oak populations is low in general like the result in this study. For instance, BERG and HAMRICK (1992) derived low estimates of differentiation $\left(G_{\mathrm{ST}}=0.032\right)$ among populations in a turkey oak $(Q$. laevis) forest by allozyme analysis. Similarly, ScHNABEL and HAMrICK (1990) showed that the variation among populations of $Q$. macrocarpa and $Q$. gambelii stands was low for both species $\left(G_{\mathrm{ST}}=\right.$ 0.076-0.119). Probably because we studied in a smaller

Table 5. - Number of found seedling, found endocarp, successfully genotyped endocarp and endocarp matched any adult in two Quercus crispula plots. The fragmented plot is a semi-fragment of natural forest from the neighbor natural forest more than $50 \mathrm{~m}$ away, while the unfragmented plot is located in the middle of an unfragmented natural forest. Both plots cover an area of $2500 \mathrm{~m}^{2}$ respectively.

\begin{tabular}{lcc}
\hline Number & Fragmented & Unfragmented \\
& plot & plot \\
\hline Found seedling & 70 & 238 \\
Found endocarp & 52 & 216 \\
Successfully genotyped endocarp & 36 & 172 \\
Endocarp matched any adult in the plot & 32 & 111 \\
The percentage of seedlings originating within the plot [\%] & 89 & 65 \\
\hline
\end{tabular}


geographical scale, the value of $F_{\mathrm{ST}}$ derived in our study was still lower than even the $G_{\mathrm{ST}}$ values in these previous studies. According to studies of pollen versus seed flow in oaks (PETIT et al., 1993), most of the gene exchanges inferred from population differentiation can be attributed to pollen flow. Details of gene flow among populations are discussed below. Additionally, large effective population size is one of the reasons for the little differentiation among populations in oak species (MuIR et al., 2004).

Similar levels of heterozygosity and allelic richness observed in the seedlings and adults in the two plots suggested that forest fragmentation did not exert serious effects to date, at least on the genetic diversity. Furthermore, sibs often grow close to each other in Q. crispula populations because of limited seed dispersal. Thereafter, the sibs would be engaged in frequent mating within each patchy structure (UBUKATA et al., 1999). Considering the results of the above mentioned study and the fact that nearly all samples were collected in the two limited areas, high values of inbreeding coefficients were expected in these plots. However, the obtained $F_{\text {IS }}$ values showed no significant deviation from zero; therefore, no evidence of inbreeding was detected. One of the possible explanations for this result is that inbreeding depression might have eliminated the individuals that were produced by sib matings (UBUKUTA $e t$ al., 1999). Further, slight decreases in the inbreeding coefficients from the seedling stage to the adult stage in the unfragmented plot or other forests (KAWAHARA et al., 2004) support this hypothesis. Such decreases were not observed in the fragmented plot; this may be attributed to other factors. Fragmentation had never promoted inbreeding, at least in this plot. Although the density of $Q$. crispula in the fragmented plot was lower than that in the other plot, the difference was probably due to the geographic factors. Particularly, the low density of the adults that germinated in the fragmented plot prior to artificial fragmentation appears to be attributable to the steep slope. This is because the seeds from the adults do not settle down under most circumstances. In fact, they roll down steep slopes that have poor soil. Even a few seeds that were able to settle on the gentle slope would grow less easily. Although we could not clarify whether artificial fragmentation had a role in the low seedling density in the fragmented plot, genetic diversity had been maintained despite the small number of adults and seedlings.

In the fragmented plot, 14 alleles were found at the seedling stage, but not at the adult stage. Such calculations can underestimate the true gene flow; however, this result confirmed gene flow into the plot. This finding is consistent with the results of the previous studies. For example, MuIR et al. (2004) examined the gene flow among seven scattered forest fragments of $Q$. petraea and found evidence of extensive gene flow, particularly via pollens. STREIFF et al. (1999) conducted paternity analysis for a mixed oak stand of $Q$. robur and $Q$. petraea and found a high percentage (averaging $65 \%$ for $Q$. robur and $69 \%$ for $Q$. petraea) of offspring that were pollinated by male parents from sources outside their 5.76-ha study site. This result is similar to our finding that the maternal parents of 62 of the 70 seedlings examined were present within the fragmented plot; however, the paternal parents of 23 of these seedlings did not appear to be present within the plot. In addition, no putative paternal trees within the plot were found for high ratios (10/16 and 12/17) of the seeds dispersed from two target adults. Thus, we can conclude that pollens can be frequently dispersed over a distance of $50 \mathrm{~m}$. In fact, STREIFF et al. (1999) concluded that the mean dispersal distance of pollen was approximately $300 \mathrm{~m}$. Recently, KoEnig and Ashley (2003) suggested that pollen flow might be limited to a much greater extent than that suspected previously. For example, the average effective distance of pollen movement was $65 \mathrm{~m}$ according to the data of 211 offspring from 21 adult valley oaks Quercus lobata (SoRK et al., 2002). However, the mean dispersal distance continues to be more than 50 $\mathrm{m}$. Although our spatial scale of observation did not permit the estimation of the long-distance dispersal, we obtained a higher value for the mean dispersal distance of pollens than that of seeds within the fragmented plot. This result supports the existence of extensive gene flow, particularly via pollen.

Inter-population seed dispersal has not been investigated as intensively as pollen dispersal. However, the contribution of the former to the total gene flow can be twice that of the latter. Therefore, it is necessary to understand the process of seed dispersal (HAMILTON, 1999). Dow and Ashley (1996) detected parent trees of 100 Q. macrocarpa saplings in a $200 \times 250 \mathrm{~m}$ stand by simple parentage exclusion. Of the 100 saplings, 32 saplings had both parent trees, while 62 saplings had only maternal trees in the stand. This result showed that almost all seeds had their origins in the stand; however, it might be due to the assumption that the seedling matched only one adult in the stand was assumed to have its maternal tree there. Similarly, in fragmented populations of the tropical tree Symphonia globulifera, ALDRICH et al. (1998) examined the demographic consequences of forest fragmentation by analyzing only leaf samples, and they suggested that the number of unique seedling genotypes per ha of fragmented forest greatly exceeded the corresponding frequency in large forests, probably due to the concentration of seeds in remnant forest fragments by foraging bats. However, there was no material evidence available for this study, similar to the endocarps. In this respect, our endocarp analysis proved that four of 36 seeds were certainly transported from sources outside the fragmented plot, although the number of samples was small because of the technical difficulties involved in extracting DNA from these tissues. Approximately $10 \%$ of seedlings originated from sources outside the plot, and this result was consistent with that obtained by simple parentage exclusion for 70 seedlings. The ratio of approximately $10 \%$ is sufficient to neutralize the negative effect of genetic drift caused by forest fragmentation; however, it was lower than the ratio $(61 / 172=35 \%)$ of the unfragmented plot.

The seeds from sources outside the fragmented plot were transported over a distance of more than $50 \mathrm{~m}$. 
Seed-dispersing animals such as Apodemus speciosus, A. argenteus, Sciurus lis, Garrulus glandarius, Nucifraga caryocatactes, and Parus varius have been identified in Chichibu Mountains (IsHIDA, 2000; SEKIJIMA et al., 2001). We have not specifically identified the seed transporter; however, rodents generally transport acorns over distances less than $50 \mathrm{~m}$. For example, MIYAKI and KIKUZAWA (1988) reported that most acorns of $Q$. crispula disseminated by mice (Apodemus specious and $A$.argenteus) traveled distances of approximately 30-40 m away from their mother trees. MigucHI and SUZUKI (1991) also found that the mean dispersal distance and the maximum dispersal distance were $13 \mathrm{~m}$ and $43 \mathrm{~m}$, respectively for the acorns of $Q$. crispula, $Q$. serrata, and $Q$. variabiris that were transported by rodents. In contrast to rodents, birds can disperse seeds over longer distances. According to IsHIDA and SATO (2002), for example, jays (Garrulus grandarius) dispersed acorns of $Q$. crispula up to 500-1500 m from their origin in the Chichibu Mountains. BERG and HAMRICK (1992) studied the regional genetic variation in turkey oak $(Q$. laevis $)$ and found that bird dispersal of acorns over distances on a scale of several kilometers could effectively enhance gene flow by wind-borne pollens; this was done by preventing inter-population differentiation among the fragmented populations. Hence, birds were the most probable candidates for the transport of $Q$. crispula seeds into the fragmented plot. In a mosaic of small fragments of mixed oak-autochtonous pine woodlands coexisting with several afforestation stands, European jays transported most of the acorns outside the oak stands, thereby decreasing the risk of intraspecific kleptobiosis (acorn pilferer) and secondary predation (GOMEZ, 2003). In our field observations, we also found many oak seedlings in the artificial forests. In this respect, the artificial forest that surrounds the fragmented plot may be a beneficial rather than a harmful habitat for birds. Irrespective of the abovementioned hypothesis, the results of the pollen and seed analyses suggest that both wind- and seed-dispersal played pivotal roles in inter-population gene flow into the plot, presumably accounting for the relatively low inbreeding coefficient of seedlings in this plot and probably preventing inbreeding depression in this oak population.

In conclusion, slight genetic divergence was observed between the examined populations of $Q$. crispula in Chichibu Mountains. The frequent gene flow among populations and/or large effective population size are the possible explanations for the slight genetic divergence. The parentage analysis in the fragmented plot showed that pollen dispersal by wind appears to promote inter-population gene flow. Seed dispersal (mainly by birds) may also contribute to inter-population gene flow, although the ratio of seed flow from sources outside the fragmented plot was lower than that of the unfragmented plot. Therefore, we observed that semi-fragmentation has not affected genetic diversity and there was no evidence of promoted inbreeding in the fragmented plot. From a practical perspective, the effects of forest semi-fragmentation, such as isolation by distances of ca. $50 \mathrm{~m}$, do not pose a grave problem for oaks in the near future. Additionally, the fragmented forests are worth conserving. Simultaneously, the transporters of genes, particularly birds, are important for conserving the fragmented populations. Therefore, seed-dispersing animals and birds should also be preserved. However, genetic diversity is slowly lost over subsequent generations, and it may take decades for the trees to lose their genetic diversity (LowE et al., 2005). The decrease in seed flow in the isolated plot after fragmentation can be a serious issue for the regeneration of $Q$. crispula in the future. Therefore, more detailed studies will be required to assess the long-term effect of forest fragmentation. In Japan, many semi-fragmented stands are scattered, particularly on partially steep slopes. Genetic connectivity among these semi-fragments will be particularly important in these areas. The Green Corridor project has been initiated to conserve such connectivity (MIURA, 1999).

\section{Acknowledgements}

Dr. K. ISHIDA, of the graduate school of agricultural and life sciences, the University of Tokyo, provided survey references and helpful advice. We are pleased to acknowledge the permission granted by Dr. S. IsHIBASHI, the former chief of the University of Tokyo's Forest in Chichibu, for us to take samples. We wish to express our gratitude to Drs. H. SAKAI and S. GoTo for permitting my sampling in the University of Tokyo's Forest in Hokkaido. Mr. Y. Watano, Mr. M. TaKagaki, Mr. K. Uchiyama, and Mr. B. Wong, the laboratory of Forest Ecosystem Studies, helped with our sampling. We wish to thank everyone mentioned above. Finally, we appreciated the constructive comments of two anonymous reviewers on an earlier draft of the manuscript.

\section{References}

ANON. (1994): Japan FAO Association Forests and Forestry in Japan, Tokyo, 65pp.

Aldrich, P., J. L. HAMrick, P. Chavarriaga and G. KOCHERT (1998): Microsatellite analysis of demographic genetic structure in fragmented populations of the tropical tree Symphonia globulifera. Molecular Ecology 7: 933-944.

Bacles, C. F. E., J. BurczyK, A. J. Lowe and R. A. Ennos (2005): Historical and contemporary mating patterns in remnant populations of the forest tree Fraxinus excelsior L.. Evolution 59: 979-990.

Bacles, C. F. E., A. J. Lowe and R. A. EnNos (2004): Genetic effects of chronic habitat fragmentation on tree species: the case of Sorbus aucuparia in a deforested Scottish landscape. Molecular Ecology 13: 573-584.

BERG, E. E. and J. L. HAMRICK (1992): Regional genetic variation in turkey oak, Quercus laevis. Canadian Journal of Forest Research 23: 1270-1274.

Cottrell, J. E., R. C. Munro, H. E. Tabbener, A. D. MilNER, G. I. ForREsT and A. J. Lowe (2003): Comparison of fine-scale genetic structure using nuclear microsatellites within two British oakwoods differing in population history. Forest Ecology and Management 176: 287-303.

Chakravarti, A. and C. C. Li (1983): The effect of linkage on paternity calculations. In: Inclusion Probabilities in Parentage Testing (ed. By R. H. WALKER), pp 411-420. American Association of Blood Banks, Arlington, VA. 
Dayanandan, S., J. Dole, K. Bawa and R. Kesseli (1999): Population structure delineated with microsatellite markers in fragmented populations of a tropical tree, Carapa guianensis (Meliaceae). Molecular Ecology 8: 1585-1592.

Dick, C.W. (2001): Genetic rescue of remnant tropical trees by an alien pollinator. Proceedings of the Royal Society of London 268: 2391-2396.

Dow, B. D. and M. V. Ashley (1996): Microsatellite analysis of seed dispersal and parentage of saplings in bur oak, Quercus macrocarpa. Molecular Ecology 5: 615-627.

Dow, B. D., M. V. Ashley and H. F. Howe (1995): Characterization of highly variable $(\mathrm{GA} / \mathrm{CT})_{\mathrm{n}}$ microsatellites in the bur oak, Quercus macrocarpa. Theoretical Applied Genetics 91: 137-141.

Godoy, J. A. and P. JoRDANo (2001): Seed dispersal by animals: exact identification of source trees with endocarp DNA microsatellites. Molecular Ecology 10: 2275-2283.

GOMEZ, J. M. (2003): Spatial patterns in long-distance dispersal of Quercus ilex acorns by jays in a heterogeneous landscape. ECOGRAPHY 26: 573-584.

Goudet, J., M. Raymond, T. DE Meeus and F. Rouseet (1996): Testing differentiation in diploid populations. Genetics 144: 1933-1940.

GOUDET, J. (2001): FSTAT, a program to estimate and test gene diversities and fixation indices. www2.unil.ch/ popgen/softwares/fstat.htm.

GRIVET, D., P. E. Smouse and V. L. SoRK (2005): A novel approach to an old problem: tracking dispersed seeds. Molecular Ecology 14: 3585-3596.

Hamilton, M. (1999): Tropical tree gene flow and seed dispersal. Nature 401: 129.

HANDA, R. (1988): Forest Policy in Japan, Tokyo, pp 526.

ISAGI, Y. (2004): Characteristics of regeneration processes of tree species occurring at low density revealed by microsatellite markers. Journal of Japanese Forestry Society 86: 169-176. (in Japanese with English abstract).

IsHIDA, K. (2000): The observation of the physical movement of bird community and mammal. The report of grant-in-aid for scientific research from 1998 to 1999: study of forest ecosystem in a long-term ecological research plot. p 56-72. (in Japanese).

IshidA, K. and D. SATo (2002): Oak seedling distribution along a long slope and acorn dispersal by Jays. Abstracts of Annual Meeting of the Japanese Forestry Society 113: 240 .

Johnson, W. C. and C. S. Adkisson (1986): Airlifting the oaks. Natural History 10: 41-46.

KaWAHARA, T., T. MATUZAKI, T. NAgAmitsu and S. IIDA (2004): Genetic diversity of Quercus crispula in Kamiashibetsu (Hokkaido) analyzed with microsatellite markers. Abstracts of Annual Meeting of the Japanese Forestry Society 115: 267.

Koenig, W. D. and M. V. Ashley (2003): Is pollen limited? The answer is blowin' in the wind. TRENDS in Ecology and Evolution 18: 157-159.

KolB, A. and M. DiEKMANN (2004): Effects of life-history traits on responses of plant species to forest fragmentation. Conservation Biology 19: 929-938.

Kominami, Y., D. Nagamatsu, T. Sato, S. SAito and H. TANOUCHI (2003): Structural changes in a tree population in an isolated stand of lucidophyllous forest. Japanese Journal of conservation ecology 8: 33-41.

KonOHIRA, Y. (1996): A discussion of forest mosaic theory. Forest Economy 577: 7-14. (in Japanese).
Lian, C., R. Oishi, N. Miyashita, K. NARA, H. Nakaya, B. Wu, Z. ZHOU and T. Hogetsu (2003): Genetic structure and reproduction dynamics of Salix reinii during primary succession on Mount Fuji, as revealed by nuclear and chloroplast microsatellite analysis. Molecular Ecology 12: 609-618.

Lowe, A. J., D. Boshier, M. Ward, C. F. E. BACles and C. NAVARRO (2005): Genetic resource impacts of habitat loss and degradation; reconciling empirical evidence and predicted theory for neotropical trees. Heredity 95: 255-273.

Mariette, S., J. Cottrell, U. M. Csaikl, P. Goikoeche, A. Konig, A. J. Lowe, B. C. van Dam, T. Barreneche, C. Bodenes, R. Streiff, K. Burg, K. Groppe, R. C. Munro, H. Tabbener and A. Kremer (2002): Comparison of levels of genetic diversity detected with AFLP and microsatellite markers within and among mixed $Q$. petraea and $Q$. robur stands. Silvae Genetica 51: 72-79.

Marshall, T. C., J. Slate, L. KruUK and J. M. Pemberton (1998): Statistical confidence for likelihood-based paternity inference in natural populations. Molecular Ecology 7: 639-655.

Miguchi, H. and T. Suzuki (1991): The role of wild mice on the regeneration of Quercus. The report of grant-in-aid for scientific research in 1990: Invasion and colonization of broad-leaf trees into the coastal forest damaged by pine wilt. p71-86. (in Japanese).

MiURA, S (1999): Wildlife and 'The Green Corridor'. Forest Technology 691: 2-7. (in Japanese).

MiYAKA, M. and K. KIKUZAWA (1988): Dispersal of Quercus mongolica acorns in a broadleaved deciduous forest 2 . Scatterhoarding by mice. Forest ecology and management 25: 9-16.

Miyamoto, A. and K. Shimada (2001): Assessing the degree of forest fragmentation in land-mosaic analysis. The research result selection (Forestry and Forest Products Research Institute). p 14-15. (in Japanese).

Mousadik, E. A. and R. J. Petit (1996): High level of genetic differentiation for allelic richness among populations of the argan tree [Argania spinosa (L.) Skeels] endemic of Morocco. Theoretical and Applied Genetics 92: 832-839.

Muir, G., A. J. Lowe, C. C. Fleming and C. Vogl (2004): High nuclear genetic diversity, high levels of outcrossing and low differentiation among remnant populations of Quercus petraea at the margin of its range in Ireland. Annals of Botany 93: 691-697.

MuRCIA, C. (1995): Edge effects in fragmented forests: implications for conservation. Trends in Ecology and Evolution 10: 58-62.

Petit, R. J., A. Kremer and D. B. Wagner (1993): Finite island model for organelle and nuclear genes in plants. Heredity 71: 630-641.

Petit, R. J., A. El MousadiK and O. Pons (1998): Identifying populations for conservation on the basis of genetic markers. Conservation Biology 12: 844-855.

SCHNABEL, A. and J. L. HAMRICK (1990): Comparative analysis of population genetic structure in Quercus macrocarpa and $Q$. gambelii (Fagaceae). Systematic Botany 15: 240-251.

SekiJima, T., M. Yamagishi, K. Ishida, K. OhmuRA and H. SAWADA (2001): Population characteristics of Apodemus argenteus and $A$. speciosus in recovery process of vegetation following deforestation. Mammalian Science 41: 1-11. (in Japanese with English abstract). 
Sork, V. L., F. W. Davis, P. E. Smouse, V. J. Apsit, R. J. Dyer, M. Fernandez and B. Kuhn (2002): Pollen movement in declining populations of California valley oak, Quercus lobata: where have all the fathers gone? Molecular Ecology 11: 1657-1668.

Steinkellner, H., S. Fluch, E. Turetschek, C. Lexer, R. Streiff, A. Kremer, K. Burg and J. Glossl (1997): Identification and characterization of $(\mathrm{GA} / \mathrm{CT})_{\mathrm{n}}$ microsatellite loci from Quercus petraea. Plant Molecular Biology 33: 1093-1096.

Streiff, R, A. Ducousso, C. Lexer, H. Steinkellner, J. Gloessl and A. Kremer (1999): Pollen dispersal inferred from paternity analysis in a mixed oak stand of Quercus robur L. and Q. petraea (Matt.) Liebl. Molecular Ecology 8: 831-841.

SUYAMA, Y. (2004): Identification of mother trees based on microsatellite analysis of maternal tissues from seeds, fruits, and seedlings. Journal of Japanese forestry society 86: 177-183. (in Japanese with English abstract).
Ubukata, M., N. Itahana and K. Kohono (1999): Examination of the mating system of Mizunara (Quercus mongolica var. grosseserrata) in a natural stand based on spatial genetic structure and inbreeding depression. Journal of Japanese forestry society 81: 280-285. (in Japanese with English abstract).

UNIVERSITY FOREST IN CHICHIBU (2002): The $9^{\text {th }}$ management and experiment plan of University Forest in Chichibu (2001-2010). University Forest 41: 1-66. (in Japanese).

Watanabe, S. (1994): Specia of Trees. Tokyo Univ. Press. Tokyo. (in Japanese).

WeIr, B. S. and C. C. Cockerham (1984): Estimating F-statistics for the analysis of population structure. Evolution 38: 1358-1370.

Young, A., T. BoYle and T. Brown (1996): The population genetic consequences of habitat fragmentation for plants. Trends in Ecology and Evolution 11: 413-418.

\title{
Date of Shoot Collection, Genotype, and Original Shoot Position Affect Early Rooting of Dormant Hardwood Cuttings of Populus
}

\author{
By R. S. Zalesny JR. ${ }^{*}$ and A. H. Wiese \\ USDA Forest Service, North Central Research Station, Forestry Sciences Laboratory, \\ 5985 Highway K, Rhinelander, WI 54501
}

(Received $9^{\text {th }}$ November 2005)

\begin{abstract}
Identifying superior combinations among date of dormant-season shoot collection, genotype, and original shoot position can increase the rooting potential of Populus cuttings. Thus, the objectives of our study were to: 1) evaluate variation among clones in early rooting from hardwood cuttings processed every three weeks from shoots collected throughout the dormant season and 2) evaluate variation among genomic groups in early rooting of the same cuttings while testing for differences among three parental shoot positions (apical, middle, basal). We tested 22 clones belonging to six genomic groups ([P. trichocarpa Torr. \& Gray $\times$ P. deltoides Bartr. ex Marsh] x $P$. deltoides 'BC', $P$. deltoides ' $\mathrm{D}$ ', $P$. deltoides $\times P$. maximowiczii A. Henry 'DM', $P$. deltoides $\times$ P. nigra L. 'DN', $P$. nigra $\times$ P. maximowiczii 'NM', $P$. trichocarpa 'T'). Cuttings, $20 \mathrm{~cm}$ long, were processed from shoots collected every three weeks beginning 1 Dec. 2003 until 9 Apr. 2004 from stool beds established at Hugo Sauer Nursery in Rhinelander, Wisconsin, USA $\left(45.6^{\circ} \mathrm{N}\right.$, $\left.89.4^{\circ} \mathrm{W}\right)$. We measured number of roots and root dry weight from harvested cuttings after 14 days of growth. The interaction between date of shoot collection and clone governed both traits $(P<0.0001)$. In general, clones exhibited the best rooting when cuttings were processed from shoots collected on or after 23 Feb. 2004.
\end{abstract}

*) Corresponding author (research plant geneticist); Phone: (715) 362-1132; Fax: (715) 362-1166; E-mail: rzalesny@fs.fed.us.
The interaction between date of shoot collection, genomic group, and shoot position governed number of roots $(P=0.0348)$ and root dry weight $(P=0.0262)$. There was broad variation in number of roots and root dry weight of apical, middle, and basal cuttings within and among genomic groups across dates of shoot collection, with 15 Mar. 2004 being an important date because differences among positions began to develop or changed relative to earlier dates. Thus, for increased plantation establishment potential with similar genotypes, we recommend collecting stool shoots no sooner than the end of February and matching cuttings of specific shoot positions to each genomic group.

Key words: Populus genomic groups, hybrid poplar, adventitious rooting, genotype $x$ environment interaction, whip, stool bed.

\section{Introduction}

Evaluation of genetic variation among and within populations of genotypes belonging to the genus Populus has been conducted for over half a century in North America (PALLARDY and KozLOWSKI, 1979; FARMER, 1970; Allen and McComb, 1956). The potential of selecting promising genotypes for numerous end-uses (including bioenergy, fiber, phytoremediation, and agroforestry) has prompted breeding of intra- and inter-species hybrids, along with gathering of open-pollinated collec- 